\title{
POTENCIALIDADES DO USO DO ZONEAMENTO DE RISCO CLIMÁTICO PARA O CULTIVO DA NOGUEIRA PECÃ (CARYA ILLINOINENSIS) NO RIO GRANDE DO SUL
}

\author{
Franciele Francisca Marmentini Rovani ${ }^{(a)}$, Cássio Arthur Wollmann ${ }^{(b)}$ \\ (a) Departamento de Geociências/Centro de Filosofia e Ciências Humanas, Universidade Federal de Santa Catarina, \\ franciele.rovani@yahoo.com.br \\ (b) Departamento de Geociências/Centro de Ciências Naturais e Exatas, Universidade Federal de Santa Maria, \\ cassiogeo@yahoo.com.br
}

\section{Eixo: CLIMATOLOGIA EM DIFERENTES NÍVEIS ESCALARES: MUDANÇAS E VARIABILIDADES}

\begin{abstract}
Resumo
O zoneamento de risco climático é um instrumento de gestão de riscos da agricultura e visa identificar os princiapais fenômenos adversos que influenciam nas fases fenológicas dos cultivos. Este trabalho teve como objetivo elaborar o zoneamento de risco climático do cultivo da nogueira pecã para o Rio Grande do Sul. Para tanto foram coletados dados climatológicos e dados das fases fenológicas do cultivo. Os dados foram organizados e espacializados por meio da krigagem ordinária e integrados por meio da álgebra de mapas do aplicativo ArcGis 10.2.2. Como resultado destaca-se o zoneamento, que integrou os cinco índices de risco: falta de horas de frio, excesso de precipitação pluviométrica, temperatura máxima superior a $35^{\circ} \mathrm{C}$, excesso de umidade relativa do ar e estiagem. $\mathrm{O}$ estado apresentou $48,4 \%$ da área com risco muito baixo e 51,6\% com risco baixo. Isto significa que este cultivo apresenta grande potencial para desenvolvimento no Rio Grande do Sul.
\end{abstract}

Palavras chave: bioclimatologia, zoneamento, nogueira pecã, Rio Grande do Sul

\section{Introdução}

Diante dos fenômenos climáticos adversos e da interferência negativa que estes causam na produção agrícola e na economia do país, instituições de pesquisa passaram a desenvolver no Brasil, a partir de 1970, mecanismos que permitissem indicar locais e datas mais apropriadas para o cultivo de determinadas culturas. Dentre esses mecanismos, destaca-se o zoneamento que pode ser dividido em quatro categorias: agrícola, agroclimático, agroecológico ou edafoclimático e de risco climático (WOLLMANN; GALVANI, 2013).

De acordo com Ometto (1981, p. 405) o zoneamento é “... a escolha dos locais mais indicados para as diversas culturas, a fim de obter-se uma maior rentabilidade do capital investido". O zoneamento de risco climático visa identificar e espacializar as áreas mais favoráveis para o desenvolvimento dos cultivos agrícolas e as áreas mais predispostas à ocorrência de fenômenos adversos durante as fases fenológicas do 
cultivo. Este instrumento tornou-se resultado da política agrícola do Ministério da Agricultura, Pecuária e Abastecimento (MAPA).

O zoneamento de risco climático pode ser definido como um instrumento de gestão de riscos da agricultura e para sua elaboração é necessário analisar as variáveis de clima, solo e planta, aplicando-se funções matemáticas e estatísticas objetivando quantificar o risco de perda das lavouras com base no histórico de ocorrência de eventos climáticos adversos (MAPA, 2010). Neste zoneamento identificam-se os principais fenômenos adversos que poderão ocorrer em determinadas fases fenológicas das culturas, estabelecendo-se assim as possíveis áreas com baixo, médio e alto risco climático.

De acordo com Maluf et al. (2001) este zoneamento pode ser aplicado no direcionamento da política e planejamento agrícola, na liberação de crédito e em seguridade rural. Além disso, Bracale (2012) destaca que na elaboração deste tipo de zoneamento é imprescindível obter dados climatológicos, conhecimento do funcionamento hídrico dos solos e das fases fenológicas dos cultivos, para que ao final, de posse do zoneamento, seja possível identificar as áreas mais favoráveis ao cultivo, diminuindo as chances das adversidades climáticas coincidirem com as fases mais sensíveis das culturas.

Considerando a importância deste zoneamento para o planejamento agrícola, a expansão do cultivo da nogueira pecã (Carya illinoinensis) na região Sul do Brasil, especialmente no estado do Rio Grande do Sul, e a falta de pesquisas científicas que enfoquem a implantação deste cultivo, seus requerimentos climáticos e adaptações, visou-se elaborar o zoneamento de risco climático para este cultivo agrícola.

\section{Materiais e Métodos}

Para o desenvolvimento desta pesquisa coletou-se dados climatológicos diários junto ao Instituto Nacional de Meteorologia (INMET) referente à temperatura máxima absoluta, temperatura média do ar, umidade relativa do ar, precipitação pluviométrica e número de horas de frio, no período de 1998 a 2013, das 23 estações meteorológicas do Rio Grande do Sul. Coletou-se também, dados de produção da nogueira pecã junto a Empresa de Assistência Técnica e Extensão Rural (EMATER/RS) e dados referentes aos requerimentos climáticos e fenologia do cultivo. Os dados climáticos foram organizados em planilhas do Microsoft Office Excel, na forma mensal e anual e realizado as análises estatísticas de tendência central e variabilidade. Em seguida, foram inseridos no banco de dados geográficos do ArcGis 10.2.2.

Para a elaboração do zoneamento definiu-se cinco índices de risco climático com base nas características climáticas da área de estudo, juntamente com as características da região de origem da nogueira, embasados nos estudos desenvolvidos por Sparks (1996; 1997; 2005) e Sierra, López e Pérez (2007).

Os cinco índices de risco climático foram definidos de acordo com as fases fenológicas em que os mesmos apresentavam ocorrências e definidos pelas classes de muito baixo, baixo, médio, alto e muito alto risco. 
$\mathrm{O}$ índice de risco de falta de horas de frio (temperaturas inferiores a $7,2^{\circ} \mathrm{C}$ ) foi elaborado no período de dormência das plantas (maio a setembro) e contemplou o intervalo de horas de frio entre 300 a 350 horas (muito baixo) até horas de frio abaixo de 150 horas (muito alto).

$\mathrm{O}$ índice de risco de temperaturas superior a $35^{\circ} \mathrm{C}$ foi analisado na polinização e floração (outubro a novembro) e na formação dos frutos (janeiro e fevereiro) com base na frequência das ocorrências do número de dias em que a temperatura máxima (Tmáx) foi superior a $35^{\circ} \mathrm{C}$, variando de até dois dias (muito baixo) até Tmáx superior a $35^{\circ} \mathrm{C}$ maior que 5 dias (muito alto).

O índice de risco de excesso de precipitação foi considerado no período de expansão foliar (setembro e outubro), floração e polinização (outubro e novembro), formação dos frutos (dezembro, janeiro e fevereiro) e na colheita (abril e maio) com base na frequência da ocorrência de dias consecutivos, variando de pluviosidade consecutiva durante 2 dias (muito baixo) até superior a 5 dias (muito alto).

O índice de risco de estiagem foi observado na estação de crescimento das nozes (outubro a abril) que compreende os estágios fenológicos de floração, formação e maturação dos frutos, considerando o intervalo de pluviosidade entre 687,5 e $750 \mathrm{~mm}$ (muito baixo) até inferior a $500 \mathrm{~mm}$ (muito alto).

O índice de excesso de umidade relativa do ar foi analisado no período de floração e polinização (outubro e novembro) com base na frequência da ocorrência de dias consecutivos com umidade relativa do ar acima de $80 \%$, considerando umidade relativa do ar acima de $80 \%$ durante 3 a 4 dias consecutivos (muito baixo) até superior a 8 dias consecutivos (muito alto).

A espacialização dos cinco índices de risco foi por meio do método da krigagem ordinária. E a integração destes ocorreu por meio da álgebra de mapas, resultando no zoneamento de risco climático.

\section{Resultados e Discussões}

O zoneamento de risco climático resultou da integração dos cinco índices de risco que foram analisados nas diferentes fases fenológicas do cultivo. De acordo com o mapa de zoneamento de risco climático da nogueira pecã para o estado, verifica-se a presença de três classes de risco: muito baixo, baixo A e baixo B (Figura 1).

A classe de risco muito baixo encontra-se em $41,8 \%$ do território gaúcho e representa as áreas em que predominaram os índices de risco muito baixo ou a ausência de riscos. Nessas áreas, prevaleceu o risco baixo de excesso de precipitação, o risco muito baixo de temperaturas superiores a $35^{\circ} \mathrm{C}$ e os riscos muito baixo e baixo de excesso de umidade relativa do ar. Destaca-se ainda por ser a zona com ausência de estiagem e da falta de foras de frio, sendo assim, a região mais indicada para o cultivo da nogueira pecã. Dentre os 20 maiores municípios produtores de nozes no Estado, destacam-se, nessa área, os municípios de Quevedos, Rondinha, Tapejara, Ciríaco, Arvorezinha, Anta Gorda, Nova Petrópolis e Barão do Triunfo. 


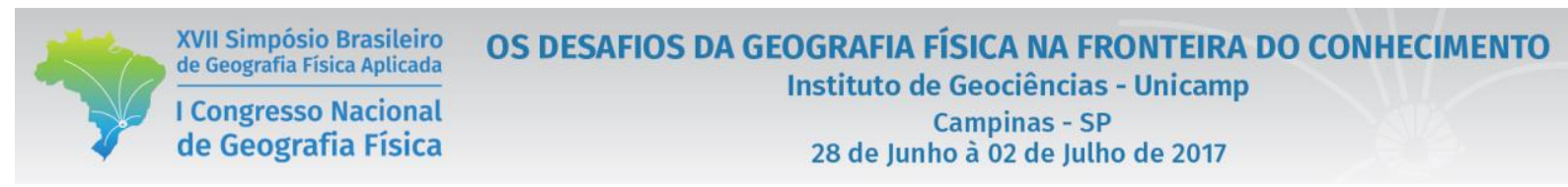

A região com predomínio do risco baixo A representa a maior parte do Estado, ou seja, 51,6\% da área total. Abrange uma área bastante diversificada, tanto em latitude, como em longitude, que se estende desde o norte até o sul e de oeste até leste, em toda a faixa litorânea. Enfatiza-se a presença de risco muito baixo e baixo com relação às temperaturas superiores a $35^{\circ} \mathrm{C}$ e excesso de precipitação, respectivamente. Apresentou risco de estiagem ao sul e risco muito baixo a médio de falta de horas de frio. Destacam-se, nessa zona de risco baixo A, os maiores municípios produtores de nogueiras tais como Santa Maria, Cachoeira do Sul, Rio Pardo, General Câmara, Cruzeiro do Sul e Iraí.

A classe de risco baixo B destaca-se em uma pequena porção situada a noroeste do Estado, na fronteira com a Argentina, e representa $6,6 \%$ da área total. Envolve principalmente pequenos municípios produtores de nozes localizados na região fronteiriça. Essa região distinguiu-se da anterior pelo fato de apresentar o predomínio da falta das horas de frio, ou seja, apesar de representar uma área de baixo risco, no que se refere às necessidades de horas de frio, apresenta risco alto e muito alto. Por outro lado, apresenta ausência do risco de estiagem e risco muito baixo quanto ao índice de excesso de precipitação. Também destaca-se por apresentar risco baixo para os índice de excesso de precipitação e temperatura superior a $35^{\circ} \mathrm{C}$.

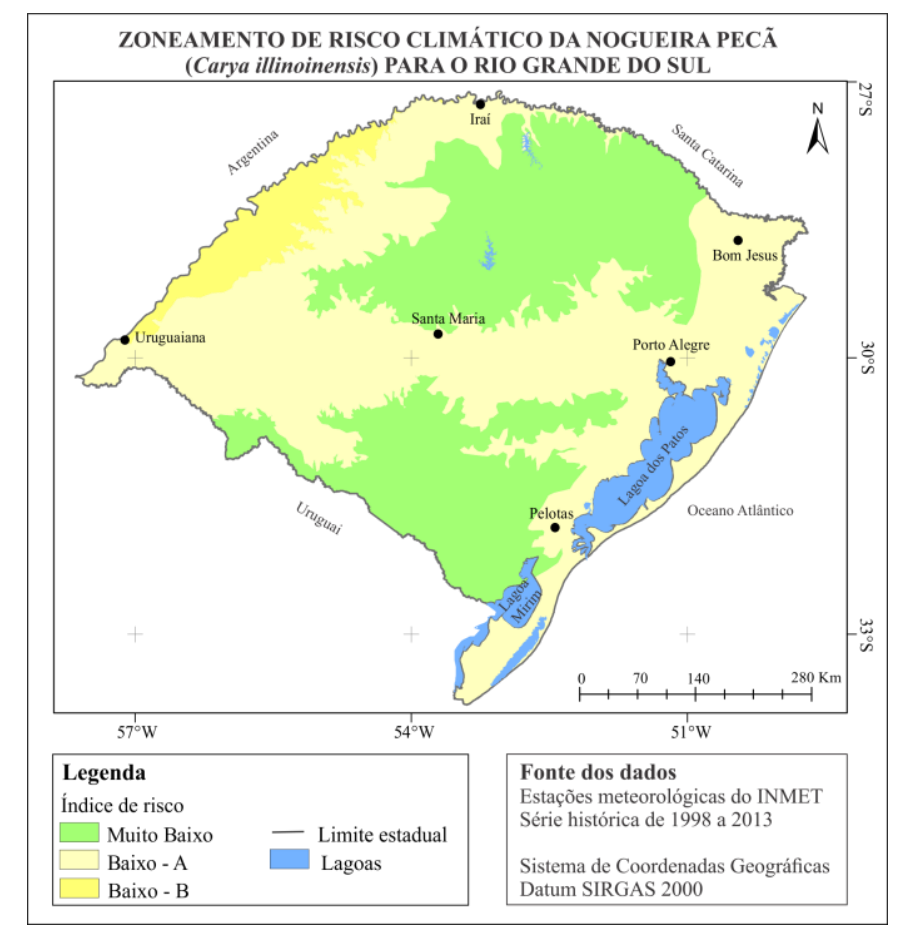

Figura 1 - Zoneamento de risco climático para o cultivo da nogueira pecã no Rio Grande do Sul.

Em ambas as zonas de risco baixo, o cultivo da nogueira pecã pode ser implantado e cultivado, porém, recomenda-se especial atenção quanto aos índices determinantes nessas áreas, pois a sua influência será refletida na produção do cultivo. Na zona de risco baixo B, o cultivo estaria condicionado ao requerimento 
de horas de frio. Orienta-se para a escolha de variedades de nogueiras que sejam menos exigentes no número de horas de frio nesses locais de risco baixo a médio. Indica-se, ainda, atentar para as condições climáticas de cada região e associá-las ao tipo de solo, buscando desenvolver um sistema de manejo adequado com acompanhamento dos requerimentos nutricionais e fitossanitários, tipos de podas visando otimizar a produção da nogueira.

\section{Considerações Finais}

O Zoneamento de risco climático apresentou o predomínio das classes de risco muito baixo (48,4\%) e baixo $(51,6 \%)$ para o território gaúcho. Isso significa que o cultivo da nogueira pecã apresenta grande potencial para o seu desenvolvimento no Rio Grande do Sul, desde que observadas às áreas de restrições quanto aos riscos climáticos. A ocorrência dos riscos climáticos não significa que a nogueira pecã não poderá ser cultiva nestas áreas. No entanto, a incidência de fenômenos adversos para o cultivo poderá acarretar interferências, principalmente na produção, por um ou mais anos.

\section{Agradecimentos}

Agradecemos a Fundação de Amparo à Pesquisa do Estado do Rio Grande do Sul (FAPERGS) e à Coordenação de Aperfeiçoamento de Pessoal de Nível Superior (CAPES) pela bolsa de doutorado da primeira autora e ao Conselho Nacional de Desenvolvimento Científico e Tecnológico (CNPq), pela concessão da bolsa de doutorado sanduíche no exterior, na Universidade do Porto.

\section{Referências Bibliográficas}

BRACALE, G. Zoneamento agrícola de risco climático. III Reunião Técnica do CEMADEN. Fortaleza: SPA/MAPA, 2012.2 Disponível em: $<$ http://www.cemaden.gov.br/cemadenarquivos/lllrtdocemaden/gustavo\%20Apres_CEMADEN_abr12.pdf $>$. Acesso em 21 set. 2015.

MALUF, J. R. T. et al. Zoneamento de riscos climáticos para a cultura do feijão no Rio Grande do Sul. Revista Brasileira de Agrometeorologia, Passo Fundo, v. 9, n. 3, p. 468 - 476, 2001.

MINISTÉRIO DA AGRICULTURA, PECUÁRIA E ABASTECIMENTO. Zoneamento Agrícola de Risco Climático: instrumento de gestão de risco utilizado pelo seguro agrícola do Brasil. 2010. Disponível em: $<$ http://www.agencia.cnptia.embrapa.br/Repositorio/Zoneameno agricola 000fl7v6vox02 wyiv80ispcrruh04mek.pdf >. Acesso em: 13 dez. 2012.

OMETTO, J. C. Bioclimatologia vegetal. São Paulo: Ed. Agronômica Ceres, 1981.

SIERRA, E. M.; LÓPEZ, E. L.; PÉREZ, S. P. Agroclimatología del pecán (Carya illinoinensis) en la Argentina. In: LAVADO, R. S.; FRUSSO, E. A. (Org.). Producción de pecán en Argentina. Buenos Aires: [s.n], p. 1-10, 2007.

SPARKS, D. A. A Climatic Model for Pecan Production under Humid Conditions. Journal of the American Society Horticultural Science. Georgia, v. 121, n. 5, p. 908 - 914, 1996.

SPARKS, D. A. A climatic model for predicting Georgia's pecan production. Proc. S. E. Pecan Growers Assn. v. 90, p. 32 - 44, 1997.

SPARKS, D. A. Adaptability of Pecan as a Species. HortScience. Georgia, v. 40, n. 5, p. $1175-1189,2005$. 


$\begin{aligned} & \text { XVII Simpósio Brasileiro } \\ & \text { de Geografia Fisica Aplicada }\end{aligned}$
$\begin{aligned} & \text { I Congresso Nacional } \\ & \text { de Geografia Física }\end{aligned}$

WOLLMANN, C. A.; GALVANI, E. Zoneamento Agroclimático: linhas de pesquisa e caracterização teórica conceitual. Sociedade \& Natureza, Uberlândia, v. 25, n. 1, p. 179-190, jan/abr. 2013. 